\title{
MAEVIA N. CORREA
}

(1914-2005)

Hay personas que hacen una importante contribución para el avance del campo en el cual se desempeñan, otras, además, dejan una impronta indeleble que ayuda al crecimiento de todos aquellos con quienes han estado en contacto. La Dra. Maevia N. Correa, "Nœmi", era una de ellas. Hasta los últimos días de su vida, fue un ejemplo de sabiduría, carácter, humildad y por sobre todas las cosas, de amor por su trabajo. Dedicó toda su vida profesional al estudio de nuestra flora con una gran vocación y una enorme capacidad de trabajo y organización.

Nació en la Ciudad de Buenos Aires el 14 de febrero de 1914. Obtuvo su título de Doctora en la Facultad de Ciencias Naturales y Museo de la Universidad Nacional de La Plata

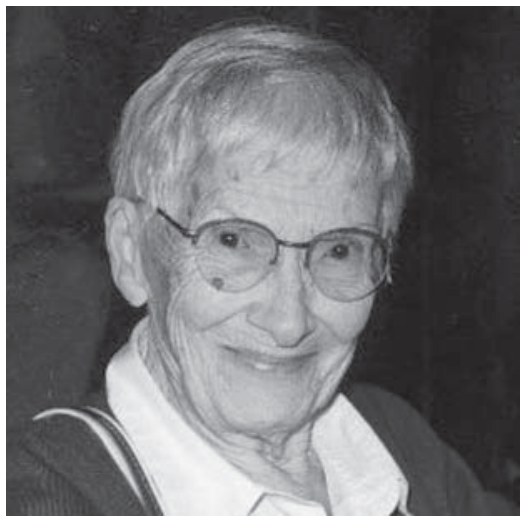
en 1953. Su maestro fue el eminente botánico Ángel L.

Cabrera, quien al darle como tema de Tesis la Revisión de las Orquídeas de la Tribu Polychondreae Schlechter, subtribu Spiranthinae Pfitzer, no sospechó la pasión que en ella se despertaría por esta familia botánica, la cual la acompañó e impulsó a seguir trabajando en ellas toda la vida.

Ya como estudiante demostró sus dotes de docente desempeñándose como Ayudante alumno de la Cátedra de Fanerógamas (1947) y luego como Ayudante diplomado de la Cátedra de Anatomía y Fisiología Vegetal (1956/58) en la Facultad donde estudiara.

Posteriormente se inició como Técnica Investigadora en el Instituto de Botánica en 1956, entonces dependiente del Ministerio de Agricultura y Ganadería de la Nación para realizar estudios taxonómicos. Luego en 1958, al crearse el INTA ingresó al Instituto de Botánica Agrícola (actual Instituto de Recursos Biológicos), del Centro Nacional de Investigaciones Agropecuarias en Castelar, primero como Técnica Investigadora (1958-1990) y luego como Investigadora Adscripta (1990-2004). También se desempeñó como Curadora del Herbario de Plantas Silvestres y Cultivadas de dicho instituto. En 1956 realizó estudios de post-grado en Anatomía, Morfología y Fisiología Vegetal, en el Departamento de Botánica de la Universidad de California, Berkeley, Estados Unidos, mediante una beca de la American Asociation of University Women (AAUW).

En 1963 inició el estudio y relevamiento de la Flora Patagónica, monumental proyecto que llevó a cabo con la colaboración de investigadores argentinos y extranjeros, y con un equipo excelente de trabajo que supo formar en el INTA con botánicos, personal del herbario, dibujantes y becarios estudiantes. Éstos, luego como profesionales, siguieron sus pasos en el estudio taxonómico de nuestra Flora y en la formación de nuevos botánicos. La exploración botánica de tan amplio territorio fue una tarea ardua, sobre todo en los primeros años por la dificultad de los caminos, la falta de buenos vehículos, el difícil acceso a muchas localidades. Además del apoyo del INTA recibió subsidios del PBI (Programa Biológico Internacional), del CONICET a través de Pro-Flora y de la National Geographic Society. Tras 36 años de trabajo, en 1999 completó la publicación de la obra que consta de 7 volúmenes, en los que se describen 2.400 especies de plantas vasculares que crecen en el área que abarca la Patagonia Argentina, Tierra del Fuego e Islas del Atlántico Sur.

Además visitó numerosos herbarios de distintos países americanos y europeos como parte de sus estudios. También colaboró con la Transecta Botánica de la Patagonia Austral, proyecto internacional llevado a cabo por el CONICET; el Instituto de la Patagonia, Chile y la Royal Society, Reino Unido, en el cual también participó el compañero de su vida personal y 
profesional, el Ing. Agr. Osvaldo Boelcke.

Pero a pesar de todo, nunca abandonó a su primer amor, las Orquídeas. El volumen II de la Flora Patagónica, pero el primero en ser publicado, lo prueba. De los casi 200 viajes de colección que realizó, además de recorrer la Patagonia, también exploró la región Chaqueña, la selva Misionera y la región de las Yungas. Como resultado publicó alrededor de 20 trabajos en los que describió, ilustró y mencionó alrededor de 74 géneros y 238 especies de orquídeas argentinas, nuevas para la ciencia o cuya presencia en nuestro país no había sido registrada con anterioridad. A pesar de su reticencia a hablar en público, dictó numerosas conferencias en congresos nacionales e internacionales y a distintos grupos de Orquideófilos del país.

En reconocimiento a su labor recibió las siguientes distinciones: Premio Cristóbal M. Hicken, correspondiente al bienio 1969-1970, por el trabajo «Chloraea, género sudamericano de Orchidáceas"; Premio de la Sociedad Argentina de Botánica por la conclusión de la obra «Flora Patagónica»y en reconocimiento a su trayectoria, 1999 y Premio de la Academia Nacional de Ciencias por la conclusión de la obra «Flora Patagónica», 1999.

Su dinamismo y energía contagiosos, su capacidad de trabajo y ejecución, su palabra certera y su agudo sentido del humor hicieron de la Dra. Correa una mujer notable, que aún luego de años de retiro oficial, siguió trabajando en sus queridas Orquídeas como Investigadora adhonorem en el Instituto de Botánica Darwinion de San Isidro, Buenos Aires. También fue Asesora Científica de la Federación de Orquideófilos de la República Argentina (F.O.R.A.) y miembro del Grupo Orquídeas de la Species Survival Commission, UICN.

Todos quienes hemos tenido la oportunidad de conocerla, y en especial, sus discípulos y amigos estamos muy agradecidos por haber tenido el privilegio de trabajar y aprender junto a Nœmi, compartir momentos gratos y a veces difíciles, en el campo, en el laboratorio o frente a una taza de té (o un vaso de whisky).

Marcela I. Sánchez. 